\title{
Developing a Mobile App (LYNX) to Support Linkage to HIV/Sexually Transmitted Infection Testing and Pre-Exposure Prophylaxis for Young Men Who Have Sex With Men: Protocol for a Randomized Controlled Trial
}

Albert Liu ${ }^{1,2}$, MD, MPH; Kenneth Coleman ${ }^{1}$, MPH; Kelly Bojan ${ }^{3,4}$, DNP; Pedro Alonso Serrano ${ }^{3,4}$, MPH; Temitope Oyedele $^{3,4}$, MD; Amayvis Garcia ${ }^{5}$; Elizabeth Enriquez-Bruce ${ }^{5}$, MD; Patricia Emmanuel ${ }^{5}$, MD; Jeb Jones ${ }^{6}$, MS, MPH, PhD; Patrick Sullivan ${ }^{6}$, DVM, PhD; Lisa Hightow-Weidman ${ }^{7}$, MD, MPH; Susan Buchbinder ${ }^{1,2}$, MD; Hyman Scott ${ }^{1,2}$, $\mathrm{MD}, \mathrm{MPH}$

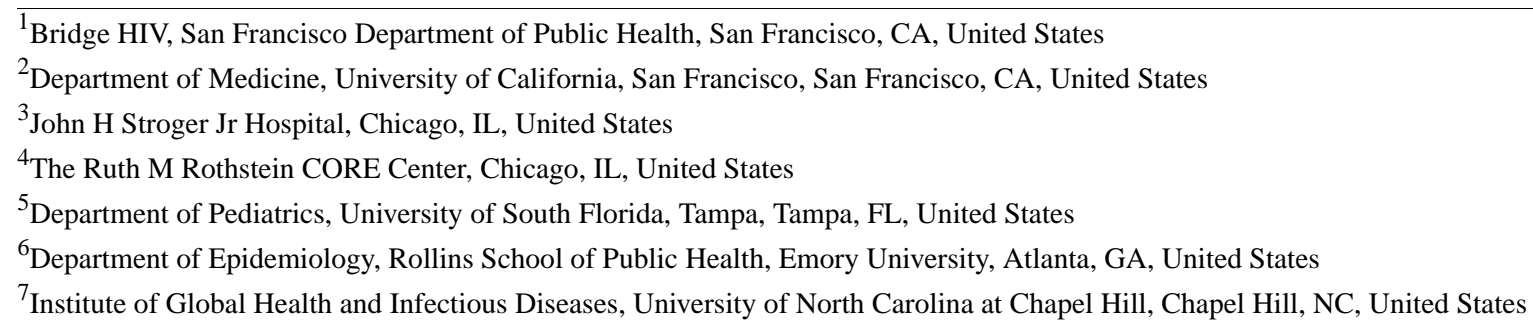

\section{Corresponding Author:}

Albert Liu, MD, MPH

Bridge HIV

San Francisco Department of Public Health

25 Van Ness Avenue

Suite 100

San Francisco, CA, 94102

United States

Phone: 14154377408

Fax: 14154317029

Email: albert.liu@sfdph.org

\begin{abstract}
Background: Young men who have sex with men (YMSM) in the United States have among the highest incidence of HIV and sexually transmitted infection (STI) and the lowest uptake of HIV and STI testing and pre-exposure prophylaxis (PrEP). Nearly universal mobile phone ownership among youth provides an opportunity to leverage mobile health apps to increase HIV/STI testing and PrEP uptake among YMSM.

Objective: The goals of this project are to develop and refine LYNX, a novel mobile app to support linkage to HIV/STIs testing and PrEP services among YMSM in the United States, and to evaluate the acceptability and feasibility of LYNX in a pilot randomized controlled trial (RCT).

Methods: This research protocol will be conducted in 3 phases: an iterative development phase with a series of 3 focus groups among 20 YMSM to refine the LYNX app; an open technical pilot among 15 YMSM to optimize usability of the app; and then a 6-month pilot RCT among 60 HIV-uninfected YMSM at risk for HIV acquisition. Developed using the Information, Motivation, and Behavioral skills theoretical model, the LYNX app includes an electronic diary to track sexual behaviors (information), a personalized risk score to promote accurate risk perception (information/motivation), testing reminders (motivation/behavioral skills), and access to home-based HIV/STI testing options and geospatial-based HIV/STI testing care sites (behavioral skills). Feasibility and acceptability will be assessed through app analytics of usage patterns and acceptability scales administered via computer-assisted self-interview at 3 and 6 months. We will also evaluate preliminary efficacy by comparing the proportion of YMSM who test at least once during the 6-month pilot and the proportion who successfully link to a PrEP provider in the intervention versus control groups.
\end{abstract}


Results: Formative work is currently underway. The LYNX pilot RCT will begin enrollment in October 2018, with study results available in 2019.

Conclusions: The LYNX app is one of the first mobile apps designed to increase HIV/STI testing and PrEP uptake among YMSM. As low-perceived risk is a barrier to HIV/STI testing and PrEP use among youth, the personalized risk assessment and interactive sexual diary in LYNX could assist YMSM in better understanding their HIV risk and providing motivation to test for HIV/STIs and initiate PrEP. Coupled with community-based recruitment, this novel mobile app has great potential to reach and engage YMSM not currently involved in care and increase rates of HIV/STI testing and PrEP uptake in this vulnerable population.

Trial Registration: ClinicalTrials.gov NCT03177512; https://clinicaltrials.gov/ct2/show/NCT03177512 (Archived by WebCite at http://www.webcitation.org/73c917wAw)

International Registered Report Identifier (IRRID): PRR1-10.2196/10659

(JMIR Res Protoc 2019;8(1):e10659) doi: 10.2196/10659

\section{KEYWORDS}

mobile app; HIV testing; sexually transmitted infections; sexually transmitted diseases; pre-exposure prophylaxis; youth; adolescent; men who have sex with men

\section{Introduction}

\section{Background}

The HIV epidemic has been worsening among young men who have sex with men (YMSM) in the United States. YMSM aged 13 to 24 years had the greatest increase $(26 \%)$ in diagnosed HIV infections from 2008 to 2011 [1], and infection rates have remained high through 2014. YMSM accounted for over one quarter of new HIV infections among MSM and over three quarters of new HIV diagnoses among youth aged 13 to 24 years in 2015 [2]. YMSM of color are disproportionately affected by HIV, with black YMSM experiencing the largest increase in new infections during this period. In 2015, black and Latino men who have sex with men (MSM) accounted for $55 \%$ and $24 \%$ of infections among YMSM, respectively. There is an urgent need for ensuring access to effective HIV prevention approaches in this vulnerable population.

HIV testing is critical for ensuring access to timely treatment and preventing ongoing transmission for HIV-infected YMSM and for linkage to effective preventive tools for those who test HIV negative. Although the Centers for Disease Control and Prevention (CDC) recommends at least yearly HIV testing for MSM [3], in a recent national Web-based survey, only 53\% of YMSM reported testing in the past year and 33\% had never tested in their lifetime [4]. Furthermore, $44 \%$ of HIV-infected youth in the United States were unaware of their diagnosis, compared with $13 \%$ of the general population [5]. Reasons for not testing can include factors at the individual, social, and structural levels [6-9] such as not having time to test (11\%), low perceived risk (42\%), and fear of testing positive/stigma (20\%) [10]. Bacterial sexually transmitted infections (STIs) have been identified as potential drivers of HIV infection [11-21]. Despite YMSM having the highest annual STI rate among any age group [22], STI screening rates are low, with less than half of YMSM reporting STI testing in the last year [10,23-30]. Low perceived risk, lack of symptoms, and lower access to health care providers have been identified as barriers to HIV/STI testing $[31,32]$.

Pre-exposure prophylaxis (PrEP) has demonstrated high efficacy, but uptake has been low among YMSM. The iPrEx trial, in which half the participants were aged under 25 years, demonstrated an estimated $>90 \%$ PrEP efficacy among MSM with detectable drug levels in blood [33,34]. Despite these results, there has been a myriad of challenges to increasing PrEP uptake in the United States, including low awareness, concerns about side effects, low risk perception, and PrEP stigma [35-38]. According to national prescription data, youth aged under 24 years are the least likely to initiate PrEP, with only $9 \%$ of PrEP initiations in 2015 occurring in this age group [39]. In a recent national survey, only half of YMSM aged 15 to 24 years had heard of PrEP and 1.7\% had ever used PrEP [40]. Demonstration projects also highlight challenges with PrEP uptake. In the US Demo Project of 550 MSM, only 20\% were age 25 years or less, and PrEP uptake was lower among younger, nonwhite, and less educated persons. Self-perceived risk was low among those declining PrEP, despite high rates of condomless sex and STIs in this group [41]. In the Adolescent Medicine Trials Network for HIV/AIDS interventions (ATN) 110 study of YMSM aged 18 to 22 years, PrEP uptake was only $16 \%$, and PrEP adherence was lower among black YMSM and declined overall during follow-up, particularly with less frequent visits [42]. Taken together, these data point to deficits in self-perceived risk that may result in low PrEP uptake, especially among YMSM of color, and the importance of engaging youth when offering and delivering PrEP.

Mobile technologies have enormous potential to reach and engage YMSM in HIV prevention [43-47]. Mobile phones have nearly reached saturation among youth, making mobile technology a particularly promising tool to reach this population that has been traditionally hard to reach through clinical services. Smartphone adoption is particularly high among young adults, with approximately $86 \%$ of those aged less than 30 years owning a smartphone. Youth are more likely to use their mobile devices for more activities such as downloading mobile apps, internet access, social networking, and accessing health information $[48,49]$, and African American and Latinx individuals are more likely to use their phones for accessing health information and educational content [50]. The expansion of smartphones' reach has increased the possibilities of dynamic, mobile phone-based HIV prevention interventions. 


\section{Theoretical Framework for Intervention}

Using the Information-Motivation-Behavior Skills (IMB) model, we have developed a highly interactive mobile app to promote accurate risk perception and increase HIV/STI testing and linkage to care among YMSM. Key components of the LYNX app will address IMB needs for both increasing HIV/STI testing frequency and PrEP uptake and are shown in Table 1. The sexual health promotion (Sex Pro) tool is an innovative Web-based app [51] that provides a personalized HIV risk score, based on data from several large MSM cohort studies [17,21,52,53]. This score is displayed on a speedometer (1-20 scale), with a higher score representing a higher level of protection, and was highly predictive of HIV risk among black MSM in HIV Prevention Trials Network (HPTN) 061, with all HIV infections occurring in individuals with a score below 16 [54]. YMSM found it particularly useful and informative but preferred a mobile app to the Web app format. Sex Pro has been developed into a mobile app, with additional features incorporated, including a sex diary to facilitate accurate data collection; HIV/STI testing information and reminders; access to a home HIV/STI testing kit ordered through a link from the app and delivered to a location of the users' choosing (eg, home or subject recruitment venue [SRV]); and access to geospatial-based testing site and linkage to HIV care information.

\section{Aims and Objectives}

This study is part of the UNC/Emory Center for Innovative Technology (iTech), which has the overall goal to develop innovative technology-focused interventions addressing the HIV prevention and care continuum for youth [55]. In this protocol, we will first refine the LYNX app through a series of focus groups (FGs) and optimize usability through a small technical pilot. We will then evaluate the acceptability and feasibility of the LYNX app in a pilot randomized controlled trial (RCT) among YMSM at risk for HIV acquisition in the United States. If found to be feasible and acceptable, LYNX will be tested for efficacy in increasing HIV testing and PrEP linkage in a separate efficacy RCT study (COMPARE) as part of the iTech. A costing analysis to determine overall per participant costs for administering the app and cost per HIV test provided and per PrEP initiation will be performed as part of COMPARE.

Table 1. LYNX components to increase HIV/STI testing and PrEP uptake, according to the Information-Motivation-Behavior Skills model.

\begin{tabular}{llll}
\hline Goal & Information & Motivation & Behavioral skills \\
\hline Increase HIV/STI ${ }^{\mathrm{a}}$ testing & $\begin{array}{l}\text { Personalized HIV risk assessment; } \\
\text { sexual history diary and partner } \\
\text { tracking }\end{array}$ & $\begin{array}{l}\text { Personalized testing reminders; } \\
\text { HIV/STI-testing diary and personalized } \\
\text { HIV risk score }\end{array}$ & $\begin{array}{l}\text { Home-based HIV/STI-testing options } \\
\text { and instructions; geospatial-based testing } \\
\text { site and linkage to HIV care information }\end{array}$ \\
Increase PrEP & $\begin{array}{l}\text { Testimonials of peers who decided to } \\
\text { take PrEP; impact of PrEP on Sex Pro }\end{array}$ & $\begin{array}{l}\text { Links to youth clinics offering PrEP; } \\
\text { app-based tips for insurance/access is- } \\
\text { sues; PrEP navigation through app chat } \\
\text { function }\end{array}$ \\
& score & & frEP educational materials \\
\end{tabular}

${ }^{\mathrm{a} S T I}$ : sexually transmitted infection.

${ }^{\mathrm{b}}$ PrEP: pre-exposure prophylaxis.

\section{Methods}

\section{Trial Registration, Ethics, Consent, and Institutional Board Approval}

This study has been reviewed and approved by the University of North Carolina institutional review board (IRB\# 17-0170). Reliance agreements were established for each SRV. A certificate of confidentiality has been obtained from the National Institute of Child Health and Human Development, and a waiver of parental consent/assent will be obtained for participants who are aged 15 to 17 years. The study is also registered on ClinicalTrials.gov (NCT03177512).

\section{Design}

This research protocol will be conducted in 3 phases: an iterative development phase with a series of FGs and in-depth interviews (IDIs) among up to 20 YMSM to refine the LYNX app; an open technical pilot among 15 YMSM to optimize usability of the app; and then a 6-month pilot RCT among $60 \mathrm{HIV-uninfected}$ YMSM at risk for HIV acquisition, in which participants are randomized 2:1 to receive the LYNX app versus standard of care.
Data in the formative phase will include videotaped FGs and IDIs, and data from the technical pilot will include a Web-based qualitative exit interview, a computer-assisted self-interview (CASI), and app analytics (including log-in times, clicks on different app pages, and completion of different app activities). For the pilot RCT, feasibility and acceptability will be assessed through app analytics of usage patterns and acceptability scales administered via CASIs. We will also evaluate preliminary efficacy by comparing the proportion of YMSM who test at least once during the 6-month pilot and the proportion who successfully link to a PrEP provider in the intervention versus control groups. All phases of this study take place in 2 diverse iTech SRV cities: Chicago, IL (study site CORE Center), and Tampa, FL (study site University of South Florida).

\section{Participants}

Eligibility criteria with a "*" are only for participants in the technical pilot and pilot RCT. Eligible participants are cisgender men who (1) are aged 15 to 24 years; (2) have not had an HIV test in the past 6 months* (3 months for the pilot RCT); (3) self-report being HIV-uninfected or HIV status unknown at screening; (4) own an iOS or Android mobile phone and willing and able to download the LYNX app; (5) are able to understand, read, and speak English; (6) are not taking PrEP*; (7) have 
self-reported evidence of being at risk for HIV acquisition, including at least one of the following in the past 6 months: (a) $\geq 1$ episode of condomless anal sex with an HIV-positive or unknown HIV status male or transfemale partner; (b) anal sex with $\geq 2$ male and/or transfemale partners; (c) exchange of money, gifts, shelter, or drugs for anal sex with a male or transfemale partner; (d) sex with a male or transfemale partner and having had an STI; or (e) if those aged 15 to 18 years who report of any anal sex with a male or transfemale partner; (8) have not received experimental HIV vaccine product with evidence of vaccine-induced seropositivity*; (9) not currently enrolled in another HIV intervention study*; and (10) do not have any health or social condition (eg, cancer requiring frequent hospitalization) that in the judgment of the investigator would make participation unsafe, complicate interpretation of study outcome data, or interfere with achieving study objectives.

To ensure inclusion of youth most impacted by HIV, we will oversample YMSM of color, with a goal of enrolling two-thirds of the cohort YMSM of color and at least one-quarter black YMSM.

\section{Recruitment}

Participants will be recruited through a variety of strategies including Web-based and social media strategies (eg, Craigslist, social networking ads, and gay networking mobile apps); distributing posters, flyers, and palm cards about the study; and direct outreach at local venues frequented by YMSM, including community-based organizations, schools, bars, social clubs, beauty parlors and/or barber shops, sports venues, churches, health fairs, balls, and other community events. Clinic-based recruitment may include reviewing medical charts of existing patients for potential eligibility or referrals from other providers in the clinic.

Potential subjects who are recruited or contact the SRV about the study will be followed up and assessed by trained SRV study staff at participating sites by phone, email, or in person. They will be informed of the nature of the study, the information to be collected, and the evaluations and assessments that are involved. Those who express interest in the study will be required to provide signed informed assent/consent and have eligibility criteria confirmed by research staff before enrolling into the study.

Everyone who is contacted for recruitment, has his medical chart reviewed to assess potential eligibility, is referred to the study by a provider, or is consented for study participation will be referred to a Web-based eligibility screener to assess eligibility. Individuals who do not consent to participate will be asked if they are willing to provide their reason for declining participation. Individuals assessed as ineligible for enrollment will have the reasons for ineligibility recorded.

\section{Description of App Intervention}

The LYNX app has been developed by Apt Mobility (www.aptmobility.com), the technical team who created the original version of the Sex Pro app and has extensive experience creating health-related apps. As shown in Table 1, the LYNX app was developed using the IMB framework to increase HIV/STI testing and PrEP uptake among YMSM. Upon downloading the LYNX app on to a personal device/phone, the user completes an onboarding process. This process includes creating log-in credentials and setting a password to access the password-protected app, entering basic demographic data, customizing user settings (eg, date, time, content of testing and reminders to use Sex Pro, and configuring rate your partner categories), and completing the baseline Sex Pro score. In addition to displaying the score, information will be provided on aspects of the participants' behaviors (eg, number of anal sex partners, condom use, and substance use) that contributed to their score. Participants are then taken to the LYNX landing screen with icons for key functions of the app, including HIV/STI testing and PrEP resources (Information); Sex Pro and earned badges (developed to integrate gamification into the app) for completing in-app activities (eg, sexual diary entries and ordering an HIV/STI home testing kit; Motivation); and HIV/STI testing instructions with access to home testing options (Behavioral Skills). All data collected by the app are stored on a secure Web-based cloud environment (Amazon Web Service) that is Health Insurance Portability and Accountability Act (HIPAA)-compliant, with a Business Associates Agreement established for secure data storage. Information is encrypted at rest on the phone and server and during transit to the secure server. Preliminary screenshots of the LYNX app prototype are shown in Multimedia Appendix 1. The LYNX app will be developed for both iOS and Android platforms, the 2 mobile phone platforms that together make up more than $97 \%$ of smartphones in the United States [56].

\section{Formative-Phase Focus Groups}

To refine the LYNX app, we will use an iterative development design using FG or individual IDI with 8 to 10 YMSM at each SRV, followed over 3 to 6 months (up to 3 iterations). Each FG or IDI will take 1 to 2 hours. Using a discussion guide, a member of the LYNX study team will demonstrate the app and wireframes (screenshots) of new components and elicit perspectives in content, layout, usability, and functionality. The IMB domains described above will guide the development process. We will also elicit feedback on the home HIV/STI testing kit and instructions and investigate preferences for documentation of clinic or home-based HIV/STI testing (release of medical records, upload test results via secure website and through the app). Participants will be asked to download and test iterative versions of the app for 2 weeks before the next FG, where we will gather feedback on the usability, design, and potential impact of the app. Study staff will use an onboarding document to walk participants through the download procedures and use of the app. FGs may be conducted in person or via videoconferencing.

All FGs and IDIs will be video-recorded for transcription and analysis. The goal of the analysis is to identify barriers and facilitators to app usability. If available, members of the app development team will observe the FGs via video conference in case they need more clarification of specific suggestions for improving the app. Analysis of the data will commence immediately after participants leave, in the form of a discussion of salient themes and suggestions. The team will then prioritize changes to the app for the next iteration to be tested and discussed in the next round of FG discussions. If further 
transcription is necessary, selected segments of the video and audio interview data will be transcribed.

\section{Technical Pilot}

After revisions to the LYNX app are completed based on the formative phase, we will conduct a 2-month, single-arm, pilot study among 12 to 15 YMSM across 2 iTech SRV cities to optimize the technical performance and functionality of LYNX. YMSM who participated in the formative phase may participate in the technical pilot, as their feedback on app revisions will provide useful insights to the development team. At an in-person enrollment visit (approximately 1.5 hours), YMSM will download the LYNX app and answer a Web-based CASI questionnaire on sociodemographics, use of technology, and risk behaviors. Study staff will use an onboarding document to walk participants through the download procedures and use of the app. Participants will then be encouraged to use all app components over the next 2 months, including ordering and using the HIV/STI test kit at least once during the technical pilot.

Upon completion of the technical pilot, all participants will complete a Web-based exit interview with qualitative-trained study staff to provide feedback on functionality, technical performance, errors and bugs encountered, overall experiences using the app, feasibility and acceptability of methods to confirm HIV testing results (eg, upload results via a secure website), and feedback for further refinement. Web-based interviews (approximately 1 hour) will be conducted via a HIPAA-compliant, video chat application (Zoom) that provides strong security components. We will also assess youth satisfaction with the app using the system usability scale (SUS), a validated assessment tool assessing various domains of the app with demonstrated high internal consistency across a number of studies [57]. Participants will be emailed a link to complete a CASI to assess these measures. Each CASI will take approximately 1 hour to complete. All exit interviews will be audio- and video-recorded and transcribed for analysis by the iTech Analytic Core (AC).

\section{Pilot Randomized Controlled Trial}

After the LYNX app is refined and optimized through the findings from the formative work and technical pilot, we will evaluate the feasibility, acceptability, and preliminary impact of LYNX through a pilot RCT with $60 \mathrm{HIV-uninfected} \mathrm{YMSM}$ at risk for HIV acquisition.

\section{Randomization}

Participants who express interest in using LYNX, meet eligibility criteria, provide informed consent, and complete a baseline assessment will be eligible for enrollment and randomization. The enrollment visit will take approximately 1.5 hours. After successful enrollment into the study, subjects will be randomized 2:1 into either the LYNX intervention arm $(\mathrm{N}=40)$ or control arm $(\mathrm{N}=20)$. The 2:1 allocation will allow us to efficiently gather additional data on app utilization. Randomization will be stratified by age ( 15 to 18 years and 19 to 24 years) and site and based on a pregenerated list created by the lead iTech AC statistician, with random blocks of size 3 or 6 [58]. After assent/consent and baseline survey completion, the participant will be randomized (assigned to the next available random allocation).

\section{LYNX Intervention Condition}

Individuals who receive LYNX will be given brief instructions on the purpose of the app, how to access it, and an overview of how to use it. Participants will be encouraged to explore all components of the app and use it routinely.

\section{Standard of Care Condition}

Following screening, participants in both conditions will receive standard of care prevention material consisting of provision of information regarding recommendations for HIV testing and referrals to local HIV testing sites and prevention services.

\section{Intervention}

Study staff will assist participants in downloading the LYNX mobile app, provide instruction on its use, and help set up reminders to input sex diary entries. To restrict access to the LYNX app to intervention arm participants only, they will be provided a single-use registration code that will need to be entered to gain access to the app. Study staff will use an onboarding document to walk participants through the download procedures and use of the app. These reminders will be personalized by the user for day, time, and message content at the first visit and can subsequently be updated by participants if desired. Participants will be encouraged to explore and use other components of the app (including the Sex Pro score, PrEP videos, bidirectional chat function with study staff, and geolocation features). Users will receive quarterly HIV/STI testing reminders using the mobile device notification feature. For confidentiality purposes, reminder notifications are nonspecific, but inside the app, the participant is linked to a customizable reminder. Reminders include 2 options for testing: (1) the ability to order a home HIV/STI testing kit to be mailed to a location of their choosing (eg, home or the SRV) free of charge or (2) a geo-located map of the closest HIV/STI testing sites. For participants who test HIV-positive during the study, information about next steps for linkage to care is included in the testing section of the app, including a phone number for an on-call clinician available 24 hours a day. In addition, there is a chat function in which participants can contact LYNX staff for support and assistance with linkage to care. Any participant who enters a positive HIV test result into the app will be contacted by the study team and provided supportive counseling and referral to treatment services.

\section{Control Arm}

Participants randomized to the control condition will be instructed to access HIV/STI testing at existing sites in the community. They will be provided with a list of these testing sites, along with an informational brochure about PrEP. All participants will be provided access to Sex Pro (risk assessment tool that is part of LYNX and will be made available on the Web) after completion of the study.

\section{Follow-Up Visits}

All enrolled participants will be followed for 24 weeks. After enrollment, all follow-up visits will occur on the Web, with SMS reminders, email, and phone follow-up conducted as 
needed to ensure completion of study procedures. Participants will complete a Web-based CASI at 12 and 24 weeks (each approximately 1 hour) and receive a stipend for completion of procedures at each visit. Visit windows will be 14 days before or after the target date.

At the 3-month visit, up to 20 participants randomized to the LYNX arm will be selected for participation in a 1.5-hour exit IDI. The purpose of the exit interviews is to elicit additional feedback on their experiences using the app, any technical difficulties encountered, and how the app could be further improved. Participants will be selected for interview using purposive sampling based on level of engagement with the app, whether participants completed HIV/STI testing and/or initiated PrEP during the study, and to achieve diversity based on sociodemographics (eg, age and race/ethnicity). Additionally, any participant who has a positive HIV test during the study will be offered an interview. By purposively sampling certain participants for the exit interviews, the goal is to select information-rich cases from which one can learn a great deal about issues of central importance to the purpose of the research [59]. All interviews will be conducted via Zoom and audio-recorded for transcription and analysis.

\section{Outcomes}

Primary and secondary outcomes and moderating variables for the pilot RCT are shown in Table 2.

The primary acceptability outcome will be measured by the SUS, a 10-item, 5-point Likert scale giving an overall view of usability. The SUS is technology-independent and provides a global measure of system satisfaction and subscales of usability and learnability [57]. A score of $>50$ (out of 100) indicates the app is acceptable [74]. We will also assess interest in future use of LYNX at study completion. For feasibility, we will assess frequency of log-ins and use of various components of LYNX, based on app analytics. If $>60 \%$ of participants open the app at least once after the initial enrollment visit, it will be considered feasible. We will also assess the proportion of YMSM who complete the personalized risk assessment, a key component of the app, and the number of HIV/STI home testing kits requested and completed. As a secondary outcome, we will evaluate the preliminary efficacy of LYNX in increasing HIV/STI testing and PrEP care linkage. For HIV testing, we will evaluate the proportion who complete at least one HIV test during the 6 months of follow-up. Self-reported HIV/STI testing via CASI will be confirmed by methods that are finalized during the formative phase (eg, medical record review and upload test results via secure website). For PrEP linkage, we will evaluate (1) the proportion of participants reporting interest in PrEP uptake during follow-up using the question "How interested are you in taking PrEP?" with response options "not at all interested, a little interested, somewhat interested, very interested, and extremely interested" compared with baseline; (2) the proportion making and attending a clinic appointment for PrEP evaluation; and (3) the proportion who receive a prescription for PrEP and the proportion who pick up PrEP medication from the pharmacy. We will request participants to sign medical release forms for the release of their HIV/STI testing results and records regarding PrEP initiation. We will also measure sexual behaviors at each quarterly follow-up visit, including numbers of partners and types of sexual behaviors, by HIV serostatus and position (insertive and receptive) in the past 3 months. Finally, we will assess IMB model constructs including HIV/STI testing and PrEP knowledge, attitudes, motivations, and behavioral skills related to HIV/STI testing and PrEP uptake. Given the importance of moderating contextual factors that may influence uptake of prevention strategies in YMSM, we will use the eco-social theoretical model which links individual, social, and structural factors (ie, socioeconomic position, social networks, and stigma) across a hierarchical framework to explore these factors as they relate to HIV/STI testing and PrEP uptake among YMSM [6-9]. Process measures including recruitment, consent, dropout, and missed visit rates will also be assessed.

\section{Statistical Analysis}

Response rates to follow-up surveys will be tabulated by recruitment venue and respondent characteristics to help understand potential sources of bias. We will characterize the study population using descriptive statistics and compare the intervention and control groups at baseline using $t$ test, Wilcoxon test, and chi-square test. The primary outcomes of the pilot RCT will be acceptability and feasibility of the app. Point estimates for mean SUS score $\geq 50$ and for proportion accessing the app $>0.60$ will be considered the minimum criteria for acceptability and feasibility, consistent with industry standards [57]. Descriptive statistics will be used to evaluate app analytics, including number of log-in attempts, cumulative time spent using the app, mean session duration, and frequency and duration of use of different components of the app. A secondary feasibility outcome will be achieved if $\geq 50 \%$ of participants who open the app complete their personalized risk score at least once.

The secondary outcomes of preliminary efficacy of the LYNX app to increase HIV/STI testing (any testing over follow-up) and PrEP uptake (as described above) will be evaluated using unadjusted risk ratios for each outcome. If there is evidence of divergence from balance in measured baseline covariates (ie, failure of randomization), post hoc analyses using Poisson regression with robust SEs [75] will be used to estimate adjusted risk ratios. Outcome variables will represent any HIV testing and any PrEP uptake over the follow-up period. Separate models will be estimated for each outcome.

With 60 participants randomized 2:1 to intervention:control and $10 \%$ to $20 \%$ attrition, we will have $80 \%$ power to detect $37 \%$ to $42 \%$ point increases in HIV testing and PrEP uptake, depending on rates in controls. The lack of precision and large minimum detectable effects, typical of pilot studies, will entail careful interpretation of study results in the light of overall patterns, plausibility, and findings from other mobile health (mHealth) studies.

\section{Incentives}

Participants receive incentives consistent with local standards for completing each study visit. This includes the US $\$ 50$ to US $\$ 60$ for the baseline visit and US \$25 to US \$30 for the 3and 6-month follow-up visits. 
Table 2. Outcomes and measures for LYNX.

\begin{tabular}{|c|c|c|}
\hline Domain & Data source & Description/scale \\
\hline \multicolumn{3}{|l|}{ Primary outcomes } \\
\hline Acceptability & $\mathrm{CASI}^{\mathrm{a}}$ & $\begin{array}{l}\text { System Usability Scale [57], Intervention Acceptability Scale [61], } \\
\text { and acceptability of app components }\end{array}$ \\
\hline Feasibility & App analytics & Frequency of app log-ins and use of different components of LYNX \\
\hline \multicolumn{3}{|l|}{ Secondary outcomes } \\
\hline HIV testing frequency & $\mathrm{CASI}, \mathrm{EP}^{\mathrm{b}}, \mathrm{MR}^{\mathrm{c}}$ & Number of HIV tests during study \\
\hline STI $^{\mathrm{d}}$ testing frequency & CASI, EP, MR & Number of STI tests during study \\
\hline HIV testing knowledge, attitudes, and behaviors & CASI & $\begin{array}{l}\text { National HIV Behavioral Surveillance men who have sex with } \\
\text { men-4 (NHBS-MSM-4) }\end{array}$ \\
\hline PrEP ${ }^{\mathrm{e}}$ knowledge and attitudes; PrEP willingness & CASI & PrEP awareness and willingness scales \\
\hline PrEP linkage & CASI, MR & HIV-negative cascade measures \\
\hline Social impacts & CASI & Social benefits and harms of using app \\
\hline \multicolumn{3}{|l|}{ Model constructs } \\
\hline Information-Motivation-Behavioral Skills (IMB) & CASI & Adapted scales based on content of app $[62,63]$ \\
\hline
\end{tabular}

\section{Covariates (based on eco-social model)[6-9]}

Individual

Demographics, socioeconomic position

Self-efficacy

CASI

Mental health (depression, anxiety)

Perceived risk of HIV infection

CASI

Trauma and abuse

\section{Social/sexual network}

Social support

Peer norms for condom use

CASI

\section{Structural}

$\mathrm{SRV}^{\mathrm{f}} /$ city
Access to health care
Incarceration history
Structural discrimination
Stigma

\section{Other covariates}

Mobile phone and technology use
Age, race/ethnicity, gender identity, sexual identity, student status, education, income, family structure, employment, insurance status, and food insecurity

Numbers and types of partners, HIV-status of partners, sexual position, and condom use

Alcohol, Smoking and Substance Involvement Screening Test (ASSIST) [64] and Alcohol Use Disorders Identification Test (AUDIT-C) [65]

HIV testing [66], PrEP use [67], condom use [68]

Generalized anxiety disorder 7-item scale and patient health questionnaire

Perceived risk of HIV scale [69]

Startle, Physiological Arousal, Anger and Numbness (SPAN) [70]

Patient-Reported Outcomes Measurement Information System (PROMIS) [71]

Geographic location of study participant

Barriers, frequency of seeing a provider, locations, and comfortability in discussing sex with provider

Ever and recent history

Everyday discrimination scale [72], racism, sexual minority stress [73], and medical mistrust

PrEP-related and sexuality-related 


\begin{tabular}{cll}
\hline Domain & Data source & Description/scale \\
\hline Mobile app use over study period & App analytics & $\begin{array}{l}\text { Login attempts, HIV testing and PrEP use, proportion complete } \\
\text { HIV-testing plan, and proportion requesting HIV/STI home test } \\
\text { kits }\end{array}$ \\
\hline
\end{tabular}

${ }^{\mathrm{a} C A S I}$ : computer-assisted self-interview.

${ }^{\mathrm{b}} \mathrm{EP}$ : electronic picture.

${ }^{\mathrm{c}} \mathrm{MR}$ : medical record confirmation.

${ }^{\mathrm{d}}$ STI: sexually transmitted infection.

${ }^{\mathrm{e}}$ PrEP: pre-exposure prophylaxis.

${ }^{\text {f }} \mathrm{SRV}$ : subject recruitment venue.

${ }^{\mathrm{g}} \mathrm{CRF}$ : case report form.

\section{Results}

This pilot RCT will begin enrolling in October 2018, and study results will be available in 2019 .

\section{Discussion}

The LYNX pilot RCT will evaluate the feasibility and acceptability of one of the first mobile apps designed to increase HIV testing and PrEP uptake among YMSM. A recent review of 285 HIV mobile apps revealed that only $8 \%$ specifically addressed MSM and none dealt with PrEP [76]. Furthermore, most were developed by nonacademic, nonpublic health developers, which may be less credible than apps created by university or health department sponsors [77]. LYNX was developed by a multidisciplinary team of public health researchers, HIV physicians, behavioral specialists, and app developers, with input from YMSM at all stages of development. Although most prior mHealth prevention interventions have focused on behavioral risk reduction alone, LYNX will incorporate components to increase HIV/STI testing and linkage to treatment and prevention services, including PrEP, and will be specifically tailored for use in YMSM.

The LYNX app will use a personalized risk assessment to assist YMSM in evaluating their risk of HIV. Internet-based personalized decision support tools have been used successfully to assist users with behavior changes in several diseases including heavy alcohol use, hyperlipidemia, and obesity [78-85]. Currently, no mHealth interventions integrate personalized HIV risk assessment, appeal to YMSM, and incorporate HIV/STI testing and resources to increase PrEP uptake [86-88]. A highly engaging risk assessment tool could assist YMSM better understand their HIV risk, provide motivation to test for HIV/STIs, and help determine when to take PrEP.
Challenges in developing mHealth interventions have been described previously and include coordination and communication with the technology developer; understanding the needs and preferences of the target population, vendors, and researchers having differing values and priorities; and extra time needed for testing and debugging the intervention [89]. To address these potential challenges in the development and testing of the LYNX app, we have established weekly calls with Apt Mobility to discuss development priorities and provide feedback on app development; established a Web-based spreadsheet to track all requests for app builds and modifications; and assigned a study coordinator with extensive experience in developing mHealth apps to manage this project. In addition, as described in this protocol, we have included extensive formative work to elicit feedback from diverse YMSM regarding their preferences and needs for content and features. Finally, we have worked with the iTech core to build realistic timelines, factoring in time required for app testing, debugging, and revisions.

In summary, a technology-based HIV prevention app has great potential in scaling up HIV/STI testing and PrEP use among YMSM. Modeling studies in MSM suggest that substantial coverage of HIV prevention services is needed to reduce population-level incidence [90], yet uptake of these services has been limited in youth. With the high penetration of smartphones among youth, LYNX has great potential to reach large numbers of high-risk YMSM who may not access medical care or traditional testing sites, at marginal incremental costs. If found to be feasible and acceptable in this pilot study, the LYNX app will be evaluated in a head-to-head comparison with the MyChoices app (Biello et al, ATN 141, submitted to this issue) in the COMPARE RCT. If effective, these apps could facilitate nationwide scale-up of HIV/STI testing and PrEP use among YMSM.

\section{Acknowledgments}

The authors would like to thank Adi Ferrara, MS, ELS, for help in the preparation of this paper; the study staff at the sites; and the YMSM who participated in this study.

\section{Conflicts of Interest}

AL has led studies for which Gilead Sciences has donated the study drug. SB has been an investigator on studies for which Gilead Sciences has donated the study drug. 


\section{Multimedia Appendix 1}

Screenshots of the LYNX app.

[PDF File (Adobe PDF File), 626KB-Multimedia Appendix 1]

\section{References}

1. CDC. Atlanta, GA: Centers for Disease Control And Prevention; 2017. HIV/AIDS Slide Sets URL: https://www.cdc.gov/ hiv/library/slidesets/index.html [accessed 2018-11-03] [WebCite Cache ID 73eM6YLx7]

2. CDC. Atlanta, GA: Centers for Disease Control and Prevention; 2016 Nov. HIV Surveillance Report: Diagnoses of HIV Infection in the United States and Dependent Areas URL: https://www.cdc.gov/hiv/pdf/library/reports/surveillance/ cdc-hiv-surveillance-report-2015-vol-27.pdf [accessed 2018-11-03] [WebCite Cache ID 73eMSLeSo]

3. DiNenno EA, Prejean J, Irwin K, Delaney KP, Bowles K, Martin T, et al. Recommendations for HIV screening of gay, bisexual, and other men who have sex with men-United States, 2017. MMWR Morb Mortal Wkly Rep 2017 Aug 11;66(31):830-832 [FREE Full text] [doi: 10.15585/mmwr.mm6631a3] [Medline: 28796758]

4. Sanchez TH, Sineath RC, Kahle EM, Tregear SJ, Sullivan PS. The annual American men's internet survey of behaviors of men who have sex with men in the United States: protocol and key indicators report 2013. JMIR Public Health Surveill 2015;1(1):e3 [FREE Full text] [doi: 10.2196/publichealth.4314] [Medline: 27227126]

5. CDC. Atlanta, GA: Centers for Disease Control and Prevention; 2015 Jul. HIV Surveillance Supplemental Report: Monitoring selected national HIV prevention and care objectives by using HIV surveillance data?United States and 6 dependent areas?2013 URL: https://www.cdc.gov/hiv/pdf/library/reports/surveillance/cdc-hiv-surveillancereport vol20 no2.pdf [accessed 2018-11-03] [WebCite Cache ID 73eMzvXUC]

6. Krieger N. Epidemiology and the web of causation: has anyone seen the spider? Soc Sci Med 1994 Oct;39(7):887-903. [Medline: 7992123]

7. Baral S, Logie CH, Grosso A, Wirtz AL, Beyrer C. Modified social ecological model: a tool to guide the assessment of the risks and risk contexts of HIV epidemics. BMC Public Health 2013 May 17;13:482 [FREE Full text] [doi:

10.1186/1471-2458-13-482] [Medline: 23679953]

8. Poundstone KE, Strathdee SA, Celentano DD. The social epidemiology of human immunodeficiency virus/acquired immunodeficiency syndrome. Epidemiol Rev 2004;26:22-35. [doi: 10.1093/epirev/mxh005] [Medline: 15234945]

9. Smith LR, Fisher JD, Cunningham CO, Amico KR. Understanding the behavioral determinants of retention in HIV care: a qualitative evaluation of a situated information, motivation, behavioral skills model of care initiation and maintenance. AIDS Patient Care STDS 2012 Jun;26(6):344-355 [FREE Full text] [doi: 10.1089/apc.2011.0388] [Medline: 22612447]

10. CDC. Atlanta, GA: Centers for Disease Control and Prevention; 2014. HIV Surveillance Special Report: HIV Risk, Prevention, and Testing Behaviors-National HIV Behavioral Surveillance System: Men Who Have Sex With Men, 20 U.S. Cities, 2011 URL: https://www.cdc.gov/hiv/pdf/HSSR 8 NHBS MSM PDF-03.pdf [accessed 2018-11-03] [WebCite Cache ID 73eNOQ430]

11. Galvin SR, Cohen MS. The role of sexually transmitted diseases in HIV transmission. Nat Rev Microbiol 2004 Jan;2(1):33-42. [doi: 10.1038/nrmicro794] [Medline: 15035007]

12. Berman SM, Cohen MS. STD treatment: how can it improve HIV prevention in the South? Sex Transm Dis 2006 Jul;33(7 Suppl):S50-S57. [doi: 10.1097/01.olq.0000175395.95911.85] [Medline: 16554696]

13. Buchbinder SP, Douglas JM, McKirnan DJ, Judson FN, Katz MH, MacQueen KM. Feasibility of human immunodeficiency virus vaccine trials in homosexual men in the United States: risk behavior, seroincidence, and willingness to participate. J Infect Dis 1996 Nov;174(5):954-961. [Medline: $\underline{8896495]}$

14. Koblin BA, Husnik MJ, Colfax G, Huang Y, Madison M, Mayer K, et al. Risk factors for HIV infection among men who have sex with men. AIDS 2006 Mar 21;20(5):731-739. [doi: 10.1097/01.aids.0000216374.61442.55] [Medline: 16514304]

15. Bernstein KT, Marcus JL, Nieri G, Philip SS, Klausner JD. Rectal gonorrhea and chlamydia reinfection is associated with increased risk of HIV seroconversion. J Acquir Immune Defic Syndr 2010 Apr 01;53(4):537-543. [doi:

10.1097/QAI.0b013e3181c3ef29] [Medline: 19935075]

16. Scott KC, Philip S, Ahrens K, Kent CK, Klausner JD. High prevalence of gonococcal and chlamydial infection in men who have sex with men with newly diagnosed HIV infection: an opportunity for same-day presumptive treatment. J Acquir Immune Defic Syndr 2008 May 01;48(1):109-112. [doi: 10.1097/QAI.0b013e318165dc0b] [Medline: 18209679]

17. Koblin BA, Chesney MA, Husnik MJ, Bozeman S, Celum CL, Buchbinder S, EXPLORE Study Team. High-risk behaviors among men who have sex with men in 6 US cities: baseline data from the EXPLORE Study. Am J Public Health 2003 Jun;93(6):926-932. [Medline: 12773357]

18. Kent CK, Chaw JK, Wong W, Liska S, Gibson S, Hubbard G, et al. Prevalence of rectal, urethral, and pharyngeal chlamydia and gonorrhea detected in 2 clinical settings among men who have sex with men: San Francisco, California, 2003. Clin Infect Dis 2005 Jul 01;41(1):67-74. [doi: 10.1086/430704] [Medline: 15937765]

19. Fleming DT, Wasserheit JN. From epidemiological synergy to public health policy and practice: the contribution of other sexually transmitted diseases to sexual transmission of HIV infection. Sex Transm Infect 1999 Feb;75(1):3-17 [FREE Full text] [doi: 10.1136/sti.75.1.3] [Medline: 10448335] 
20. Zetola NM, Bernstein KT, Wong E, Louie B, Klausner JD. Exploring the relationship between sexually transmitted diseases and HIV acquisition by using different study designs. J Acquir Immune Defic Syndr 2009 Apr 15;50(5):546-551 [FREE Full text] [doi: 10.1097/QAI.0b013e318195bd2b] [Medline: 19367993]

21. Buchbinder SP, Vittinghoff E, Heagerty PJ, Celum CL, Seage GR, Judson FN, et al. Sexual risk, nitrite inhalant use, and lack of circumcision associated with HIV seroconversion in men who have sex with men in the United States. J Acquir Immune Defic Syndr 2005 May 01;39(1):82-89. [Medline: 15851918]

22. Centers for Disease Control and Prevention. CDC. Atlanta, GA: Department of Health and Human Services; 2015. Sexually Transmitted Disease Surveillance URL: https://www.cdc.gov/std/stats14/surv-2014-print.PDF [accessed 2018-11-03] [WebCite Cache ID 73eNZvdY7]

23. Bourne C, Knight V, Guy R, Wand H, Lu H, McNulty A. Short message service reminder intervention doubles sexually transmitted infection/HIV re-testing rates among men who have sex with men. Sex Transm Infect 2011 Apr;87(3):229-231. [doi: 10.1136/sti.2010.048397] [Medline: 21296796]

24. Centers for Disease Control Prevention. HIV testing among men who have sex with men—21 cities, United States, 2008. MMWR Morb Mortal Wkly Rep 2011 Jun 03;60(21):694-699 [FREE Full text] [Medline: 21637183]

25. Kellerman SE, Lehman JS, Lansky A, Stevens MR, Hecht FM, Bindman AB, et al. HIV testing within at-risk populations in the United States and the reasons for seeking or avoiding HIV testing. J Acquir Immune Defic Syndr 2002 Oct 01;31(2):202-210. [Medline: 12394799]

26. McDaid LM, Hart GJ. Contact with HIV prevention services highest in gay and bisexual men at greatest risk: cross-sectional survey in Scotland. BMC Public Health 2010 Dec 31;10:798 [FREE Full text] [doi: 10.1186/1471-2458-10-798] [Medline: 21194448]

27. Miller LG, Simon PA, Miller ME, Long A, Yu EI, Asch SM. High-risk sexual behavior in Los Angeles: who receives testing for HIV? J Acquir Immune Defic Syndr 1999 Dec 15;22(5):490-497. [Medline: 10961611]

28. Makulowich GS. HIV and STD prevention update. Multisite HIV prevention trial. AIDS Patient Care STDS 1998 Sep;12(9):725-727. [doi: 10.1089/apc.1998.12.725] [Medline: 15468447]

29. Fuqua V, Chen YH, Packer T, Dowling T, Ick TO, Nguyen B, et al. Using social networks to reach Black MSM for HIV testing and linkage to care. AIDS Behav $2012 \mathrm{Feb}$;16(2):256-265. [doi: 10.1007/s 10461-011-9918-x] [Medline: 21390535]

30. Finlayson TJ, Le B, Smith A, Bowles K, Cribbin M, Miles I, Centers for Disease Control Prevention. HIV risk, prevention, and testing behaviors among men who have sex with men-National HIV Behavioral Surveillance System, 21 U.S. cities, United States, 2008. MMWR Surveill Summ 2011 Oct 28;60(14):1-34 [FREE Full text] [Medline: 22031280]

31. MacKellar DA, Valleroy LA, Secura GM, Behel S, Bingham T, Celentano DD, Young Men's Survey Study Group. Perceptions of lifetime risk and actual risk for acquiring HIV among young men who have sex with men. AIDS Behav 2007 Mar;11(2):263-270. [doi: 10.1007/s10461-006-9136-0] [Medline: 16791527]

32. Dorell CG, Sutton MY, Oster AM, Hardnett F, Thomas PE, Gaul ZJ, et al. Missed opportunities for HIV testing in health care settings among young African American men who have sex with men: implications for the HIV epidemic. AIDS Patient Care STDS 2011 Nov;25(11):657-664. [doi: 10.1089/apc.2011.0203] [Medline: 21923415]

33. Grant RM, Lama JR, Anderson PL, McMahan V, Liu AY, Vargas L, et al. Preexposure chemoprophylaxis for HIV prevention in men who have sex with men. N Engl J Med 2010 Dec 30;363(27):2587-2599 [FREE Full text] [doi: 10.1056/NEJMoa1011205] [Medline: 21091279]

34. Anderson PL, Glidden DV, Liu A, Buchbinder S, Lama JR, Guanira JV, iPrEx Study Team. Emtricitabine-tenofovir concentrations and pre-exposure prophylaxis efficacy in men who have sex with men. Sci Transl Med 2012 Sep 12;4(151):151ra125 [FREE Full text] [doi: 10.1126/scitranslmed.3004006] [Medline: 22972843]

35. Saberi P, Gamarel KE, Neilands TB, Comfort M, Sheon N, Darbes LA, et al. Ambiguity, ambivalence, and apprehensions of taking HIV-1 pre-exposure prophylaxis among male couples in San Francisco: a mixed methods study. PLoS One 2012;7(11):e50061 [FREE Full text] [doi: 10.1371/journal.pone.0050061] [Medline: 23166819]

36. Fuchs JD, Sobieszczyk ME, Madenwald T, Grove D, Karuna ST, Andrasik M, HVTN 505 Protocol Team. Intentions to use preexposure prophylaxis among current phase 2B preventive HIV-1 vaccine efficacy trial participants. J Acquir Immune Defic Syndr 2013 Jul 01;63(3):259-262 [FREE Full text] [doi: 10.1097/QAI.0b013e318296df94] [Medline: 23614998]

37. Krakower DS, Mimiaga MJ, Rosenberger JG, Novak DS, Mitty JA, White JM, et al. Limited awareness and low immediate uptake of pre-exposure prophylaxis among men who have sex with men using an internet social networking site. PLoS One 2012;7(3):e33119 [FREE Full text] [doi: 10.1371/journal.pone.0033119] [Medline: 22470438]

38. Liu A, Cohen S, Follansbee S, Cohan D, Weber S, Sachdev D, et al. Early experiences implementing pre-exposure prophylaxis (PrEP) for HIV prevention in San Francisco. PLoS Med 2014 Mar;11(3):e1001613 [FREE Full text] [doi: 10.1371/journal.pmed.1001613] [Medline: 24595035]

39. Bush S, Ng L, Magnuson D, Piontkowsky D, Giler R. Significant Uptake of Truvada for Pre-Exposure Prophylaxis (PrEP) Utilization in the US in Late 2014-1Q2015. 2015 Presented at: IAPC IAPAC Treatment, Prevention, and Adherence Conference; June 28-30, 2015; Miami, FL URL: http://www.iapac.org/AdherenceConference/presentations/ADH10 OA74. pdf

40. Sullivan P, Sineath C, Kahle E, Sanchez T. Awareness, willingness and use of oral pre-exposure prophylaxis (PrEP) among a national sample of US men who have sex with men. In: AIDS IMPACT 2015, Abstract 2362. 2015 Presented at: AIDS 
Impact; July 28-31,2015; Amsterdam, Netherlands URL: http://www.aidsimpact.com/2015/Academics/Programme/abstract/ ?id=2362

41. Cohen SE, Vittinghoff E, Bacon O, Doblecki-Lewis S, Postle BS, Feaster DJ, et al. High interest in preexposure prophylaxis among men who have sex with men at risk for HIV infection: baseline data from the US PrEP demonstration project. J Acquir Immune Defic Syndr 2015 Apr 01;68(4):439-448 [FREE Full text] [doi: 10.1097/QAI.0000000000000479] [Medline: 25501614]

42. Hosek SG, Rudy B, Landovitz R, Kapogiannis B, Siberry G, Rutledge B, et al. An HIV Preexposure Prophylaxis Demonstration Project and Safety Study for Young MSM. J Acquir Immune Defic Syndr 2017 Dec 01;74(1):21-29 [FREE Full text] [doi: 10.1097/QAI.0000000000001179] [Medline: 27632233]

43. Gold J, Lim MS, Hocking JS, Keogh LA, Spelman T, Hellard ME. Determining the impact of text messaging for sexual health promotion to young people. Sex Transm Dis 2011 Apr;38(4):247-252. [doi: 10.1097/OLQ.0b013e3181f68d7b] [Medline: 20966830]

44. Holloway IW, Cederbaum JA, Ajayi A, Shoptaw S. Where are the young men in HIV prevention efforts? Comments on HIV prevention programs and research from young men who sex with men in Los Angeles county. J Prim Prev 2012 Dec;33(5-6):271-278 [FREE Full text] [doi: 10.1007/s10935-012-0282-z] [Medline: 23132515]

45. Eyrich-Garg KM. Mobile phone technology: a new paradigm for the prevention, treatment, and research of the non-sheltered "street" homeless? J Urban Health 2010 May;87(3):365-380 [FREE Full text] [doi: 10.1007/s11524-010-9456-2] [Medline: 20397058]

46. Riley WT, Rivera DE, Atienza AA, Nilsen W, Allison SM, Mermelstein R. Health behavior models in the age of mobile interventions: are our theories up to the task? Transl Behav Med 2011 Mar;1(1):53-71 [FREE Full text] [doi: 10.1007/s13142-011-0021-7] [Medline: 21796270]

47. Muessig KE, Pike EC, Fowler B, LeGrand S, Parsons JT, Bull SS, et al. Putting prevention in their pockets: developing mobile phone-based HIV interventions for black men who have sex with men. AIDS Patient Care STDS 2013 Apr;27(4):211-222 [FREE Full text] [doi: 10.1089/apc.2012.0404] [Medline: 23565925]

48. Anderson M. Pew Internet. 2015. Technology Device Ownership: 2015 URL: http://www.pewinternet.org/2015/10/29/ technology-device-ownership-2015 [accessed 2018-11-03] [WebCite Cache ID 73ePbSdhO]

49. Smith A. Pew Internet. 2015. US Smartphone Use in 2015 URL: http://www.pewinternet.org/2015/04/01/ us-smartphone-use-in-2015/2015/ [accessed 2018-11-03] [WebCite Cache ID 73ePoGy1p]

50. Anderson M. Pew Research Center. 2015. Racial and ethnic differences in how people use mobile technology URL: http:/ /www.pewresearch.org/fact-tank/2015/04/30/racial-and-ethnic-differences-in-how-people-use-mobile-technology/ [accessed 2018-11-03] [WebCite Cache ID 73ePw71wq]

51. Sex Pro. San Francisco, CA: San Francisco Department of Public Health; 2015. Welcome to Sex Pro! URL: https://mysexpro. org/en/home/ [accessed 2018-11-09] [WebCite Cache ID 73nReY8Nt]

52. Bartholow BN, Goli V, Ackers M, McLellan E, Gurwith M, Durham M, et al. Demographic and behavioral contextual risk groups among men who have sex with men participating in a phase 3 HIV vaccine efficacy trial: implications for HIV prevention and behavioral/biomedical intervention trials. J Acquir Immune Defic Syndr 2006 Dec 15;43(5):594-602. [doi: 10.1097/01.qai.0000243107.26136.82] [Medline: 17003693 ]

53. Koblin BA, Mayer KH, Noonan E, Wang CY, Marmor M, Sanchez J, et al. Sexual risk behaviors, circumcision status, and preexisting immunity to adenovirus type 5 among men who have sex with men participating in a randomized HIV-1 vaccine efficacy trial: step study. J Acquir Immune Defic Syndr 2012 Aug 01;60(4):405-413 [FREE Full text] [doi: 10.1097/QAI.0b013e31825325aa] [Medline: 22421748]

54. Scott H, Vittinghoff E, Irvin R, Liu A, Fields S, Magnus M. Sex Pro: A Personalized HIV Risk Assessment Tool for Men Who Have Sex With Men. 2015 Presented at: CROI 2015; February 23-26, 2015; Seattle, WA URL: http://www. croiconference.org/sessions/sex-pro-personalized-hiv-risk-assessment-tool-men-who-have-sex-men

55. Hightow-Weidman LB, Muessig K, Rosenberg E, Sanchez T, LeGrand S, Gravens L, et al. University of North Carolina/Emory Center for Innovative Technology (iTech) for Addressing the HIV Epidemic Among Adolescents and Young Adults in the United States: Protocol and Rationale for Center Development. JMIR Res Protoc 2018 Aug 03;7(8):e10365 [FREE Full text] [doi: 10.2196/10365] [Medline: 30076126]

56. Statista. 2017. Subscriber share held by smartphone operating systems in the United States from January 2012 to June 2017 URL: https://www.statista.com/statistics/266572/market-share-held-by-smartphone-platforms-in-the-united-states/ [accessed 2018-11-03] [WebCite Cache ID 73eQbwvew]

57. Brooke J. SUS: a quick and dirty usability scale. In: Jordan P, Thomas BW, McClelland I, editors. Usability Evaluation in Industry. London, UK: Taylor and Francis; 1996:189-194.

58. Kernan WN, Viscoli CM, Makuch RW, Brass LM, Horwitz RI. Stratified randomization for clinical trials. J Clin Epidemiol 1999 Jan;52(1):19-26. [doi: 10.1016/S0895-4356(98)00138-3] [Medline: 9973070]

59. Patton MQ. Qualitative interviewing. Qual Health Res 2002;3:344-347 [FREE Full text]

60. Rotheram-Borus MJ, Wu Z, Liang L, Li L, Detels R, Guan J, NIMH Collaborative HIV/STD Prevention Trial Group. Reductions in sexually transmitted infections associated with popular opinion leaders in China in a randomised controlled trial. Sex Transm Infect 2011 Jun;87(4):337-343 [FREE Full text] [doi: 10.1136/sti.2010.046243] [Medline: 21278400] 
61. Horvath KJ, Oakes JM, Rosser BR, Danilenko G, Vezina H, Amico KR, et al. Feasibility, acceptability and preliminary efficacy of an online peer-to-peer social support ART adherence intervention. AIDS Behav 2013 Jul;17(6):2031-2044 [FREE Full text] [doi: 10.1007/s10461-013-0469-1] [Medline: 23553347]

62. Fisher CM. Are information, motivation, and behavioral skills linked with HIV-related sexual risk among young men who have sex with men? J HIV AIDS Soc Serv 2011;10(1):5-21 [FREE Full text] [doi: 10.1080/15381501.2011.549064] [Medline: 21731473]

63. Misovich S, Fisher W, Fisher J. A measure of AIDS prevention, information, motivation, behavioral skills, and behavior. In: Davis C, Yarber W, Bauserman R, Schreer G, Davis S, editors. Handbook of Sexuality Related Measures. Thousand Oaks, CA: Sage; 1998:328-337.

64. WHO ASSIST Working Group. The Alcohol, Smoking and Substance Involvement Screening Test (ASSIST): development, reliability and feasibility. Addiction 2002 Sep;97(9):1183-1194. [Medline: 12199834]

65. Bradley KA, DeBenedetti A, Volk RJ, Williams EC, Frank D, Kivlahan DR. AUDIT-C as a brief screen for alcohol misuse in primary care. Alcohol Clin Exp Res 2007 Jul;31(7):1208-1217. [doi: 10.1111/j.1530-0277.2007.00403.x] [Medline: 17451397]

66. Jamil MS, Guy RJ, Bavinton BR, Fairley CK, Grulich AE, Holt M, FORTH Investigator Group. HIV testing self-efficacy is associated with higher HIV testing frequency and perceived likelihood to self-test among gay and bisexual men. Sex Health 2017 Apr;14(2):170-178. [doi: 10.1071/SH16100] [Medline: 27883311]

67. Erlen JA, Cha ES, Kim KH, Caruthers D, Sereika SM. The HIV Medication Taking Self-efficacy Scale: psychometric evaluation. J Adv Nurs 2010 Nov;66(11):2560-2572 [FREE Full text] [doi: 10.1111/j.1365-2648.2010.05400.x] [Medline: 20722799]

68. Rotheram-Borus M, Murphy D, Coleman C, Kennedy M, Reid H, Cline T, et al. Risk acts, health care,medical adherence among HIV+ youths in care over time. AIDS and Behavior 1997;1(1):43-52 [FREE Full text] [doi: 10.1023/A:1026213905034]

69. Napper LE, Fisher DG, Reynolds GL. Development of the perceived risk of HIV scale. AIDS Behav 2012 May;16(4):1075-1083 [FREE Full text] [doi: 10.1007/s10461-011-0003-2] [Medline: 21785873]

70. Meltzer-Brody S, Churchill E, Davidson JR. Derivation of the SPAN, a brief diagnostic screening test for post-traumatic stress disorder. Psychiatry Res 1999 Oct;88(1):63-70. [doi: 10.1016/s0165-1781(99)00070-0]

71. Hahn EA, Devellis RF, Bode RK, Garcia SF, Castel LD, Eisen SV, et al. Measuring social health in the patient-reported outcomes measurement information system (PROMIS): item bank development and testing. Qual Life Res 2010 Sep;19(7):1035-1044 [FREE Full text] [doi: 10.1007/s11136-010-9654-0] [Medline: 20419503]

72. Williams DR, Yan Y, Jackson JS, Anderson NB. Racial differences in physical and mental health: socio-economic status, stress and discrimination. J Health Psychol 1997 Jul;2(3):335-351. [doi: 10.1177/135910539700200305] [Medline: 22013026]

73. Hatzenbuehler ML, Nolen-Hoeksema S, Erickson SJ. Minority stress predictors of HIV risk behavior, substance use, and depressive symptoms: results from a prospective study of bereaved gay men. Health Psychol 2008 Jul;27(4):455-462. [doi: 10.1037/0278-6133.27.4.455] [Medline: 18643003]

74. Bangor A, Kortum P, Miller J. Determining what individual SUS scores mean: adding an adjective rating scale. J Usability Stud 2009;4(3):114-123 [FREE Full text]

75. Spiegelman D, Hertzmark E. Easy SAS calculations for risk or prevalence ratios and differences. Am J Epidemiol 2005 Aug 01;162(3):199-200. [doi: 10.1093/aje/kwi188] [Medline: 15987728]

76. Sullivan PS, Jones J, Kishore N, Stephenson R. The roles of technology in primary HIV prevention for men who have sex with men. Curr HIV/AIDS Rep 2015 Dec;12(4):481-488. [doi: 10.1007/s11904-015-0293-5] [Medline: 26519083]

77. Goldenberg T, McDougal SJ, Sullivan PS, Stekler JD, Stephenson R. Preferences for a mobile HIV prevention app for men who have sex with men. JMIR Mhealth Uhealth 2014 Oct 29;2(4):e47 [FREE Full text] [doi: 10.2196/mhealth.3745] [Medline: 25355249]

78. Sheehan J, Sherman KA. Computerised decision aids: a systematic review of their effectiveness in facilitating high-quality decision-making in various health-related contexts. Patient Educ Couns 2012 Jul;88(1):69-86. [doi: 10.1016/j.pec.2011.11.006] [Medline: 22185961]

79. Stacey D, Bennett CL, Barry MJ, Col NF, Eden KB, Holmes-Rovner M, et al. Decision aids for people facing health treatment or screening decisions. Cochrane Database Syst Rev 2011(10):CD001431. [doi: 10.1002/14651858.CD001431.pub3] [Medline: 21975733]

80. Doumas DM, Hannah E. Preventing high-risk drinking in youth in the workplace: a web-based normative feedback program. J Subst Abuse Treat 2008 Apr;34(3):263-271. [doi: 10.1016/j.jsat.2007.04.006] [Medline: 17600650]

81. Kypri K, McCambridge J, Cunningham JA, Vater T, Bowe S, De Graaf B, et al. Web-based alcohol screening and brief intervention for Māori and non-Māori: the New Zealand e-SBINZ trials. BMC Public Health 2010;10:781 [FREE Full text] [doi: 10.1186/1471-2458-10-781] [Medline: 21176233]

82. Harle CA, Downs JS, Padman R. Effectiveness of personalized and interactive health risk calculators: a randomized trial. Med Decis Making 2012;32(4):594-605. [doi: 10.1177/0272989X11431736] [Medline: 22247421] 
83. Wagener TL, Leffingwell TR, Mignogna J, Mignogna MR, Weaver CC, Cooney NJ, et al. Randomized trial comparing computer-delivered and face-to-face personalized feedback interventions for high-risk drinking among college students. J Subst Abuse Treat 2012 Sep;43(2):260-267. [doi: 10.1016/j.jsat.2011.11.001] [Medline: 22197301]

84. Grover SA, Lowensteyn I, Joseph L, Kaouache M, Marchand S, Coupal L, Cardiovascular Health Evaluation to Improve ComplianceKnowledge Among Uninformed Patients (CHECK-UP) Study Group. Patient knowledge of coronary risk profile improves the effectiveness of dyslipidemia therapy: the CHECK-UP study: a randomized controlled trial. Arch Intern Med 2007 Nov 26;167(21):2296-2303. [doi: 10.1001/archinte.167.21.2296] [Medline: 18039987]

85. Soureti A, Murray P, Cobain M, Chinapaw M, van Mechelen W, Hurling R. Exploratory study of web-based planning and mobile text reminders in an overweight population. J Med Internet Res 2011 Dec 20;13(4):e118 [FREE Full text] [doi: 10.2196/jmir.1773] [Medline: 22182483]

86. Muessig KE, Pike EC, Legrand S, Hightow-Weidman LB. Mobile phone applications for the care and prevention of HIV and other sexually transmitted diseases: a review. J Med Internet Res 2013;15(1):e1 [FREE Full text] [doi: 10.2196/jmir.2301] [Medline: 23291245]

87. Menza TW, Hughes JP, Celum CL, Golden MR. Prediction of HIV acquisition among men who have sex with men. Sex Transm Dis 2009 Sep;36(9):547-555 [FREE Full text] [doi: 10.1097/OLQ.0b013e3181a9cc41] [Medline: 19707108]

88. Carpenter KM, Stoner SA, Mikko AN, Dhanak LP, Parsons JT. Efficacy of a web-based intervention to reduce sexual risk in men who have sex with men. AIDS Behav 2010 Jun;14(3):549-557 [FREE Full text] [doi: 10.1007/s10461-009-9578-2] [Medline: 19499321]

89. Horvath K, Ecklund AM, Hunt SL, Nelson TF, Toomey TL. Developing internet-based health interventions: a guide for public health researchers and practitioners. J Med Internet Res 2015 Jan 23;17(1):e28 [FREE Full text] [doi: 10.2196/jmir.3770] [Medline: 25650702]

90. Carnegie NB, Goodreau SM, Liu A, Vittinghoff E, Sanchez J, Lama JR, et al. Targeting pre-exposure prophylaxis among men who have sex with men in the United States and Peru: partnership types, contact rates, and sexual role. J Acquir Immune Defic Syndr 2015 May 01;69(1):119-125 [FREE Full text] [doi: 10.1097/QAI.0000000000000555] [Medline: 25942463]

\section{Abbreviations}

ATN: Adolescent Medicine Trials Network

CASI: computer-assisted self-interview

CRF: case report form

EP: electronic picture

FG: focus group

IDI: in-depth interview

IMB: Information-Motivation-Behavioral Skills

mHealth: mobile health

MR: medical record confirmation

MSM: men who have sex with men

PrEP: pre-exposure prophylaxis

RCT: randomized controlled trial

Sex Pro: sexual health promotion

SRV: subject recruitment venue

STI: sexually transmitted infection

SUS: System Usability Scale

YMSM: young men who have sex with men

Edited by A Pettifor, B Mustanski, I Holloway, S Allison, R Schnall; submitted 31.03.18; peer-reviewed by L Young, W Brown, A
Rudolph; comments to author 14.05.18; revised version received 08.07.18; accepted 13.09.18; published 25.01.19
Please cite as:
Liu A, Coleman K, Bojan K, Serrano PA, Oyedele T, Garcia A, Enriquez-Bruce E, Emmanuel P, Jones J, Sullivan P, Hightow-Weidman
L, Buchbinder S, Scott H
Developing a Mobile App (LYNX) to Support Linkage to HIV/Sexually Transmitted Infection Testing and Pre-Exposure Prophylaxis
for Young Men Who Have Sex With Men: Protocol for a Randomized Controlled Trial
JMIR Res Protoc $2019 ; 8(1):$ e10659
URL: $\underline{\text { http://www.researchprotocols.org/2019/1/e10659/ }}$
doi: $10.2196 / 10659$
PMID: $\underline{30681964}$


(C)Albert Liu, Kenneth Coleman, Kelly Bojan, Pedro Alonso Serrano, Temitope Oyedele, Amayvis Garcia, Elizabeth Enriquez-Bruce, Patricia Emmanuel, Jeb Jones, Patrick Sullivan, Lisa Hightow-Weidman, Susan Buchbinder, Hyman Scott. Originally published in JMIR Research Protocols (http://www.researchprotocols.org), 25.01.2019. This is an open-access article distributed under the terms of the Creative Commons Attribution License (https://creativecommons.org/licenses/by/4.0/), which permits unrestricted use, distribution, and reproduction in any medium, provided the original work, first published in JMIR Research Protocols, is properly cited. The complete bibliographic information, a link to the original publication on http://www.researchprotocols.org, as well as this copyright and license information must be included. 